\title{
DIGITAL ENGAGEMENT AND THE MODERN CULTURAL TOURIST
}

\section{Kevin Griffin}

School of Hospitality Management and Tourism,

Dublin Institute of Technology,

Dublin, Ireland
Correspondence:

Kevin Griffin

e-mail:

kevin.griffin@dit.ie

\begin{abstract}
:
The focus of this discussion paper is the relationship between digital technology and cultural tourism. Having presented culture, tourism and cultural tourism, the paper suggests that cultural tourists are actively seeking an engaging experience. Whether one uses the interpretation principles of Tilden, or Csíkszentmihályi's concept of 'Flow', tourist engagement is heavily influenced by storytelling, and uninterrupted, engaging encounters. To serve the visitor, cultural sites must realise that 'provocation' and relating to the individual are of paramount importance for deep and meaningful experience. Thus, a challenge is presented in this paper, whereby cultural sites might consider the opportunities for digital-detox for their visitors, in an effort to provide more meaningful interaction and depth of experience, instead of unquestioningly committing to investment in digital technologies.
\end{abstract}

Keywords:

Culture, Heritage, Tourism, Social Media, Digital, Engagement, Flow

\section{INTRODUCTION}

Since the beginning of the 21st Century, the world has been increasingly approaching digital saturation, with almost $75 \%$ of western Europeans regularly using the internet in 2017, and 62\% owning a smartphone (McNair, 2017). As the world of business tries to cope with this revolution, marketeers are developing a new vocabulary for younger digitally literate generations: Gen Y, Gen Z, Digital Natives (as opposed to 'Digital Immigrants'), Millennials, post-Millennials etc. Koulopoulos and Keldsen (2014) suggest that one of the major forces that society faces is hyperconnectivity between people computers, machines and objects. The speed and nature of this change is highly challenging for institutions and organisations, with Prensky (2001) in Digital Natives, Digital Immigrants, going so far as to admonishing educators for not catering to the needs and requirements of the modern student. In fact, he suggests that the current generational mis-match is responsible for falling education standards in countries such as the USA, where the traditional processes of teaching are not communicating to modern, digitally-dependent students. In this paper it is suggested that a similar disconnect exists between those managing cultural visitor attractions and sites, and their tech-savvy and tech 
dependent visitors. However, it is posited, that instead of sites adopting more digital technology, that they need to question the need for such tools. Perhaps, they should focus on raising the standards of their traditional methods of visitor engagement which are still valid and useful for engaging with digitally saturated, culture seeking visitors, who might benefit from digital detox, and a resultant real engagement with humans, sites and stories.

\section{CULTURE AND TOURISM}

The focus of this paper is thus, the relationship between digital technology and cultural tourism / the cultural tourist. However, culture is a slippery concept for which no simple or single, universally accepted definition exists. Despite its wooly elusiveness, 2018 has been designated by the EU, as the European Year of Cultural Heritage with the aim to 'encourage more people to discover and engage with Europe's cultural heritage, and to reinforce a sense of belonging to a common European space'. In establishing this event, the EU announced that the refrain for the year would be 'Our heritage: where the past meets the future' (EU, 2018), what an interesting statement as we consider the relationship between cultural heritage and digital technology.

The establishment of this year-long celebration arises from the belief that culture and heritage have intrinsic value for all people, and it behoves us all to both preserve and pass this on to future generations. The EU acknowledge that cultural heritage is not static, it is dynamic and evolves as people interact with it, thus, they see cultural heritage as something central to who we are and a vital element in the future development of Europe (EU, 2018). In exploring this topic during 2018, the European Cultural Heritage Summit, Europa Nostra outlined the key characteristics of European cultural heritage (see Figure 1).

Figure 2. The Importance of Cultural Heritage in Europe

- It is what makes us European, reflecting our varying and shared values, cultures and memories.

- It captures the multiple layers of our continuously evolving identity - local, regional, national, and European

- It feeds both our sense of belonging to a local community and the sense of togetherness and solidarity in Europe

- It connects generations / reflects movements of people and ideas over many centuries of shared history.

- It ensures a bridge between our past and our future, drawing on history while inspiring creativity and innovation.

- It is a key driver for sustainable development \& enhanced social cohesion \& source of rewarding jobs

- It brings harmony and beauty to our living environment, both man-made and natural improves our wellbeing and quality of life.

(Europa Nostra, 2018:2)

One way for people to engage with cultural heritage is through tourism. However, neither the EU, nor Europa Nostra make a very strong link between the two. Perhaps this is because 'cultural tourism' is even more convoluted to comprehend than either tourism or culture separately, with both of these terms being notoriously difficult to grasp (Griffin et al., 2013). McKercher and du Cros (2012) note the complexity of defining the term, cultural tourism, suggesting that it can be considered from four perspectives: tourism derived definitions, motivational definitions, experiential or aspirational definitions and operational definitions. In their writings, they distil cultural tourism down to comprising of four simple elements: tourism; the use of cultural heritage assets; consumption of experiences and products and; the tourist. Where these four elements come together, cultural tourism occurs. Figure 2, which illustrates the EU's conceptualisation of cultural heritage, could be seen as a broad classification of cultural tourism that maps quite well onto various notions of the cultural tourism product - see chapter 4 of Raj, Griffin and Morpeth (2013) for a discussion of various models. 
Figure 1. The many shapes and forms of Cultural Heritage

\begin{tabular}{cl}
\hline Tangible & buildings, monuments, artefacts, clothing, artwork, books, machines, historic towns, archaeological sites. \\
\hline Intangible & $\begin{array}{l}\text { practices, representations, expressions, knowledge, skills - and the associated instruments, objects and } \\
\text { cultural spaces - that people value. This includes language and oral traditions, performing arts, social } \\
\text { practices and traditional craftsmanship. }\end{array}$ \\
\hline Natural & landscapes, flora and fauna. \\
\hline Digital & $\begin{array}{l}\text { resources that were created in digital form (for example digital art or animation) or that have been digi- } \\
\text { talised as a way to preserve them (including text, images, video, records) }\end{array}$ \\
\hline
\end{tabular}

Source : EU, 2018

In many spheres of tourism, the final say is given to the World Tourism Organisation, and Cultural Tourism is no different. Eventually, in 2017, the UNWTO adopted the following definition of Cultural Tourism:

Cultural tourism is a type of tourism activity in which the visitor's essential motivation is to learn, discover, experience and consume the tangible and intangible cultural attractions / products in a tourism destination.

These attractions / products relate to a set of distinctive material, intellectual, spiritual and emotional features of a society that encompasses arts and architecture, historical and cultural heritage, culinary heritage, literature, music, creative industries and the living cultures with their lifestyles, value systems, beliefs and traditions (cited in UNWTO, 2018:11).

\section{THE CULTURAL TOURIST}

Both academics (see again McKercher \& Du Cros, 2002, also the likes of Ashworth, 1995; Richards, 2007; Smith, 2003; Smith and Robinson, 2006; Smith and Richards, 2015; Vong, 2016) and tourism development agencies (i.e. Visit Britain, ND; Fáilte Ireland, ND; EU, 2018b), have researched and published extensively about cultural tourism and the cultural tourist. Much of the most recent literature leans heavily on the 2009 OECD report: The Impact of Culture on Tourism, from whence phrases emanate such as 'cultural tourism accounts for 40\% ... of international tourism' (OECD, 2009:21 citing UNWTO data) or 'Cultural tourism is particularly attractive because of the raft of benefits it can deliver to local communities' (OECD, 2009:22). The unquestioning recycling of these phrases (most recently in the UNWTO 2018 publication: Tourism and Culture Synergies) means that there is a universal, benign acceptance for the importance of cultural tourism.

It is not suggested here that these claims regarding the importance of culture in tourism are incorrect or misleading, however, the zeal and fervour exhibited by those who 'produce', manage, sell and advocate this 'product' justifies more critical reflection and analysis. And, if this market is indeed so large, a more refined approach to marketing and managing of cultural tourism is required.

\section{EXPERIENCE SEEKING CULTURAL TOURISTS}

In their highly informative Global Segmentation Toolkit, Fáilte Ireland (c.2014) present a profile of what they call the 'Culturally Curious' market segment:

Typically, Culturally Curious travellers are out to broaden their minds and expand their experience by exploring new landscapes, history and culture. They are curious about everything... [They] love to discover history and always find ways of getting real insight. They are looking to encounter new places and experiences... [They] like to feel that they have not only broadened their mind but also immersed themselves in a place... They like people to show an interest and educate them - to feel they've connected. They really appreciate personal guides. 
These are what McKercher \& Du Cros (2002) call 'purposeful cultural tourists' and what Ontario Ministry of Tourism (2009) call 'tourists wholly motivated by culture'. They want meaningful, deep, engaged experiences with the cultural tourism product that they encounter. When these visitors engage with encounters that satisfy their desire for cultural contact, memorable cultural experiences happen, and the individual becomes more loyal and feels more engaged (Chen \& Rahman, 2018).

The question is, how can the tourism industry facilitate this level of engagement with experience seeking cultural tourists? In attempting to tackle this challenge, two models are presented. The first of these is Tilden's Six Principles of Interpretation.

\section{TILDEN AND STORYTELLING}

While it was first published in 1957, Tilden's Six Principles of Interpretation (Figure 3) still provides a valid framework for interpreting heritage and culture that is still heavily used by authors seeking to understand the processes of visitor engagement (see for example, Andrioli, 2017; Rahaman, \& Kiang, 2017; Weber, 2018).

Figure 3. Tilden's Six Principles of Interpretation

- Interpretation that does not somehow relate what is being displayed or described to something within the personality or experience of the visitor will be sterile.

- Information, as such, is not interpretation. Interpretation is revelation based upon information. But they are entirely different things. However, all interpretation includes information.

- Interpretation is an art, which combines many arts. Whether the materials presented are scientific, historical or architectural. Any art is in some degree teachable.

- The chief aim of interpretation is not instruction, but provocation.

- Interpretation should aim to present a whole rather than a part and must address itself to the whole [person] rather than any phase.

- Interpretation addressed to children (say up to the age of twelve) should not be a dilution of the presentation to adults but should follow a fundamentally different approach. To be at its best it will require a separate programme.

(Tilden, 1957)

Analysed, evaluated and explored by academics and practitioners for 70 years, the core message of Tilden's principles is centred on the process of provocative storytelling. There are fascinating parallels between Tilden's work of and that of marketing guru Philip Kotler, who uses terms such as 'storytelling' and 'content marketing' in his step by step guide to developing a digital campaign. Presented as cutting-edge advice for the marketing world, Kotler's ideas focus on audience mapping, planning and creating content suited to 'a specific audience subset' - themes which directly resonate with the work of Tilden (Kotler et al., 2017:126). From a marketing perspective, the tourism industry has embraced storytelling, evidenced in practices such as consultants advocating the establishment of 'Destination Storytelling Stakeholders Networks' (Economía Creativa Consultancy, 2016), and tourism development agencies stating: 'we believe stories are the key to making [our destination] stand out in the crowded travel marketplace' (Fáilte Ireland, NDb). This is mirrored at the level of the cultural tourism attraction, where storytelling is also being encouraged. For an example see the website of 'Emotive', an EU-funded heritage project that aims 'to use emotional storytelling to dramatically change how we experience heritage sites' (Emotive, 2018).

In many instances, product managers, in an attempt to be unique, are adopting new technologies. Thus, terms such as augmented reality, virtual reality, computer visualisation, 3D modelling and virtual tours are not out of place in cultural heritage sites where smart guides, touch screens and interactive technologies are 
becoming the norm. The question arises however, do these technologies provide deep and meaningful experiences for our cultural tourists? To answer this, we need to tease out the process of engagement, and thus, explore the work of Mihály Csíkszentmihályi relating to the concept of 'Flow'.

\section{CSÍKSZENTMIHÁLYI AND FLOW}

Perhaps it is a little unusual to present a theory related to 'positive psychology' when discussing cultural tourism. However, any fan of music, who gets 'lost' in a piece by their favourite artist, any fan of cinema who is transported to a far-off galaxy while watching a film, or any history buff, who imagines themselves in times of yore while wandering around a medieval castle knows exactly what it is to 'engage' with an experience. Taking this experiential engagement to a higher level can result in 'flow' (Csikszentmihalyi, 1990). The following table presents a number of characteristics of flow.

Figure 4. Csikszentmihalyi - The Characteristics of Flow

- Intense and focused concentration on what one is doing in the present moment

- Merging of action and awareness

- Loss of reflective self-consciousness (i.e., loss of awareness of oneself as a social actor)

- A sense that one can control one's actions; that is, a sense that one can in principle deal with the situation because one knows how to respond to whatever happens next

- Distortion of temporal experience (typically, a sense that time has passed faster than normal)

- Experience of the activity as intrinsically rewarding, such that often the end goal is just an excuse for the process.

(Nakamura\& Csikszentmihalyi, 2009)

Flow is not a passive experience, and for the individual there must be a balance between the level of skill utilised and the challenge that is being presented. When this happens, the individual achieves a sublime level of satisfaction and reward. Thus, linking 'flow', to heritage and cultural sites, in parallel with the work of Tilden, 'provocation' and relating to the individual are of paramount importance for deep and meaningful experience.

How can we facilitate self-actualisation and engagement as demonstrated in 'flow' theory? According to research into workplace productivity by Griffith (2014), achieving flow can be a challenge, and it is seriously hampered by interruptions such as email and meetings. If employees are allowed to turn off technology, they become more productive, and are more likely to attain 'flow'. A range of online self-help authors (such as Carter, 2015) provide guidelines on achieving 'flow', with many of them supporting the necessity to avoid digital (and other) distractions. Despite insistence by many, human beings cannot effectively multi-task (Goldhill, 2015), we operate most effectively, when we are uninterruptedly engaging with a single task. According to On Marketing (2015), researchers have been exploring 'simultaneous media use' (now manifest in the activity of 'multiscreening') since the 1930s, when they investigated the impact of subjects undertaking tasks while listening to the radio. Modern marketeers such as Peszko (2015), are excited about the sales prospects of managing how multiscreen viewers engage in shifting, stacking and meshing (processes of engaging with secondary screens while watching TV etc.); and technology experts (i.e. McGill et al. 2015) are investigating ways for multiple viewers to utilise the same screen in an independent manner. However, this proliferation of technology might facilitate a greater volume of engagement, but the depth of experience is questionable, and it is suggested here, that in fact $\mathrm{t}$ is highly superficial. Thus, there is a growing awareness for the need to engage with 'digital detox'. Whether this time away from technology is undertaken for emotional, religious, political moral, physical recovery, addiction, or privacy reasons (Morrison and Gomez, 2014) it is posited that the cultural tourist might benefit from digital detox, in an attempt to provide uninterrupted opportunities for 'flow'. The problem, however, is that many sites are pushing in exactly the opposite direction, as they raise the stakes in the digital interpretation arms-race. 
Purveyors and experts in the digital domains are enthusiastically encouraging cultural and heritage attractions to engage with technology. Bluntly stating 'our mission is to get cultural institutions to use digital media in a more effective way' (Visser \& Richardson, 2013), they offer infographic rich, glossy, high-end brochures, catalogues and images to dazzle and impress potential clients, encouraging curators and site managers to spend their hard-earned budgets on the latest gadgets. Websites such as www.digitalmeetsculture.net bring cultural and digital domains together, however, does this resonate with the cultural tourist as identified in the outset of this paper. Product providers are being coerced and cajoled into committing large budgets into these tools, for fear of being left behind. However, discussion with site managers, personal engagement with sites and engagement with visitors suggests that many cultural tourists are either overwhelmed or underwhelmed by these expensive technologies.

The core message in this paper is to examine the role of technology in mediating cultural tourism experiences, and drawing to a close, it is worrying to think that the marriage between cultural heritage sites and technology seems at best to be a strained one. Data related to return on investment in digital technology is absent from the discussion. In-depth analysis on the impact of technology such as work undertaken by Krösbacher in 2010 suggesting that many visitors prefer to experience attractions without technological aids, is sparse. However, there is a constant industry push towards digital mediation of cultural heritage experiences, despite ample evidence that technology interrupts the 'flow' of experiential encounters. Descriptors of 'the cultural tourist' describe individuals who are seeking experiences to engage in active opportunities for 'gaze' (Urry, 1999) and 'flow', rather than seeking digital enhancement and mediation. However, managers and operators are often distracted / blinded by the attractive must-have toys of digital interpretation.

It is this author's belief that digital mediation, while presenting wonderful opportunities for cultural heritage interpretation, is still in its infancy. These technologies require deep and meaningful research, to understand the impact and influences they have on visitors' experiences related to the sites and narratives they are engaging with. In the meantime, the next time I go to a cultural heritage site, I promise that I will (somewhat begrudgingly) switch off my phone; as advised by Tilden, I will seek to be provoked by the story that is being told instead of distracted by technology; and I will attempt to attain a level of engagement that will facilitate a Csikszentmihalyi state of 'flow'.

\section{REFERENCES}

Andrioli, A.J. (2017). Risky Business Provocation and Interpretation, The Gettysburg Compiler: On the Front Lines of History. Retrieved from https://cupola.gettysburg.edu/compiler/220

Ashworth, G.J. (1995). Managing the Cultural Tourist. In Ashworth, G.J. \& Dietvorst, A.G.J. (Eds.), Tourism and spatial transformations: implications for policy and planning. Wallingford: CAB International, 265284.

Griffith, T. (2014). Help your Employees find Flow. Harvard Business Review. Retrieved from https://hbr.org/ 2014/04/help-your-employees-find-flow

Carter, C.L. (2015). 3 Steps to Finding Your Flow: Clear your mind, build a fortress, breathe, focus, and watch what happens, Psychology Today. Retrieved from https://www.psychologytoday.com/us/blog/raisinghappiness/201509/3-steps-finding-your-flow

Chen, H., \& Rahman, I. (2018). Cultural tourism: An analysis of engagement, cultural contact, memorable tourism experience and destination loyalty, Tourism Management Perspectives, Vol. 26: 153-163.

Csikszentmihalyi, M. (1990). Flow: The Psychology of Optimal Experience. New York: Harper and Row.

Economía Creativa Consultancy (2016). Creative storytelling for tourism audience development. Retrieved from https://www.slideshare.net/AntonioCarlos11/creative-storytelling-for-tourism-audience-developmentsep-2016-by-economia-creativa-consultancy

Emotive (2018) Emotive is. Retrieved from https://emotiveproject.eu/

EU (2018). The European Year of Cultural Heritage 2018. Retrieved from https://europa.eu/cultural-heritage/ about_en 
EU (2018b) Cultural Tourism. Retrieved from http://www.failteireland.ie/Supports/Develop-your-tourismenterprise/Attract-Cultural-Tourists.aspx

Europa Nostra (2018). The Berlin Call To Action Cultural Heritage For The Future Of Europe. Retrieved from http://www.europanostra.org/wp-content/uploads/2018/09/Berlin-Call-Action-Eng.pdf

Fáilte Ireland (2014 c). Growing International Sales: Global Segmentation Toolkit, using segmentation to win international sales. Dublin: Fáilte Ireland.

Fáilte Ireland (ND). Attract Cultural Tourists. Retrieved from http://www.failteireland.ie/Supports/Developyour-tourism-enterprise/Attract-Cultural-Tourists.aspx

Fáilte Ireland (ND b). Telling our stories together. Dublin: Fáilte Ireland.

Griffin, K., Raj, R., \& Morpeth, N. (2013). Introduction to Cultural Tourism Philosophy and Management, In Raj, R. Griffin, K. and Morpeth, N. Cultural Tourism, CABI, Wallingford, 1-12.

Kotler, P., Kartajaya, H., \& Setiawan, I. (2017) Marketing 4.0: moving from traditional to digital. New Jersey: Wiley.

Krosbacher, M.C. (2010) Authenticity and the Use of Multimedia at Cultural Tourist Attractions, Doctoral Thesis, Dublin Institute of Technology, Dublin. Retrieved from https://arrow.dit.ie/appadoc/20/

Koulopoulos, T., \& Keldsen, D. (2014). Gen Z Effect: The six forces facing the future of business. New York: Routledge.

McGill, M., Williamson, J.H., \& Brewster, S.A. (2015). A review of collocated multi-user TV: Examining the changing role of the TV in the multi-viewer, multi-screen home. Personal and Ubiquitous Computing, 19(5-6): 743-759.

McKercher, B., \& du Cros, H. (2012) Cultural Tourism: the partnership between tourism and cultural heritage management. New York: Routledge.

McNair, C. (2017) Internet and Mobile Users in Europe: eMarketer's Country-by-Country Forecast for 2017-2021. Retrieved from https://www.emarketer.com/Report/Internet-Mobile-Users-Europe-eMarketers-Country-by-Country-Forecast-20172021/2002177

Morrison, S., \& Gomez, R. (2014) Pushback: The Growth of Expressions of Resistance to Constant Online Connectivity, iConference 2014 Proceedings: 1-15. Retrieved from https://www.ideals.illinois.edu/bitstream/ handle/2142/47322/008_ready.pdf?sequence $=2$

Nakamura, J. \& Csikszentmihalyi, M. (2009) The Concept of Flow, In Snyder C.R. and Lopez, S.J. (eds) Oxford Handbook of Positive Psychology, Oxford University Press: 89-105

OECD (2009). The Impact of Culture on Tourism. Paris: OECD.

On Marketing (2015). Multiscreening and Simultaneous Media Use: Unlocking the Golden Age of Digital Advertising. Retrieved from Forbes.com: https://www.forbes.com/sites/onmarketing/2014/03/17/multiscreening-and-simultaneous-media-use-unlocking-the-golden-age-of-digital-advertising/\#3e43790c56ba

Ontario Ministry of Tourism (2009). Ontario Cultural and Heritage Tourism Product Research Paper. Ontario: Queen's Printer for Ontario.

Peszko, K. (2015). Multiscreening as a way of reaching a consumer - idea and possibilities. Jagiellonian Journal of Management, Vol. 4:339-351

Prensky, M. (2001). Digital Natives, Digital Immigrants. On the Horizon, 9(5) 1-6.

Rahaman, H., \& Kiang, T.B. (2017). Digital Heritage Interpretation: Learning from the Realm of Real-World. Journal of Interpretation Research, 22(2):53-64.

Richards, G. (2007). Cultural Tourism: Global and Local Perspectives. London: The Haworth Press.

Smith, M.K., \& Robinson, M. (2006). Cultural Tourism in a Changing World: Politics, Participation and (re) presentation. Channel View Publications

Smith, M.K. (2003). Issues in Cultural Tourism Studies. London: Routledge.

Smith, M.K., \& Richards, G. (2015). The Routledge Handbook of Cultural Tourism. London: Routledge.

Storry, M., \& Childs, P. (1997). British Cultural Identities. London: Routledge.

Tilden, F. (1957). Interpreting Our Heritage: Principles and Practices for Visitor Services in Parks, Museums, and Historic Places. North Carolina: University of North Carolina Press.

Urry, J. (1990). The Tourist Gaze: leisure and travel in contemporary societies. London: Sage Publications.

Visit Britain (ND) Culture and Heritage Topic Profile. Retrieved from https://www.visitbritain.org/sites/default/ files/vb-corporate/Documents-Library/documents/Culture_and_Heritage_Topic_Profile_Full.pdf 
Vong, F. (2016). Application of cultural tourist typology in a gaming destination - Macao. Current Issues in Tourism, 19:9, 949-965

Weber, E.A. (2018). Heritage Interpretation as Tool in Cross-Cultural Communication: Challenges and Solutions in the Work of Guides-Interpreters. Journal of Siberian Federal University, Humanities \& Social Sciences, Vol. 7: 1161-1170

World Tourism Organization (2018). Tourism and Culture Synergies. Madrid: UNWTO. 